\title{
The aging anesthesiologist: a narrative review and suggested strategies
}

\section{L'anesthésiologiste vieillissant: synthèse narrative et stratégies suggérées}

\author{
Alan D. Baxter, MD • Sylvain Boet, MD • \\ Dennis Reid, MD • Gary Skidmore, MD
}

Received: 20 January 2014 / Accepted: 10 June 2014 / Published online: 2 July 2014

(C) The Author(s) 2014. This article is published with open access at Springerlink.com

\begin{abstract}
Purpose To address an aging anesthesia workforce, we review the relevant changes and implications associated with age in order to stimulate discussion at the individual, local, and national levels regarding appropriate changes in practice aimed at protecting patient safety.

Principal findings In a 2013 survey of Canadian Anesthesiologists, $22 \%$ were aged 55-64 yr, 7\% were aged 65-74 yr, and 3\% were older than 74 yr. Clinical abilities decline with age, making older anesthesiologists more likely than their younger colleagues to be associated with adverse patient events. Anesthesiologists older than 65 yr in Ontario, Quebec, and British Columbia had 50\% more cases involving litigation and almost twice the number of cases involving severe patient injury compared with anesthesiologists younger than 51 yr of age. In the absence of overt deterioration in skills, decisions about reducing activities and retirement are left largely to individuals despite their limited ability to self-assess competence. This state of affairs may contribute to the
\end{abstract}

This article is accompanied by an editorial. Please see Can J Anesth 2014; 61: this issue.

Author contributions Alan Baxter was responsible for the concept of the article. Sylvain Boet wrote the Simulation section. Dennis Reid and Gary Skidmore wrote the Medicolegal section. All authors were involved in the revision of the manuscript prior to submission.

A. D. Baxter, MD $(\varangle) \cdot$ S. Boet, MD $~ D$. Reid, MD .

G. Skidmore, MD

The Department of Anesthesiology, Faculty of Medicine, Ottawa

Hospital Research Institute, The Ottawa Hospital, University of

Ottawa, General Campus, 501 Smyth Rd, Critical Care Wing

1401, Ottawa, ON K1H 8L6, Canada

e-mail: abaxter@ottawahospital.on.ca increased incidence of adverse events and poor patient outcomes.

Conclusions Provincial regulatory bodies have peer assessment programs to evaluate physicians at random, following a complaint, and at certain ages, but all have limitations. Simulation has been used widely for training and assessment in the aviation industry as well as in automobile driving exams. Simulation can assess crisis recognition and management, which is crucial in anesthesiology and not well assessed by other methods, and could assist elderly anesthesiologists during the preretirement phase of their careers. A standardized schedule for winding down would have advantages for physicians, their department, and their patients. A suggested schedule might include no further on-call duties for those aged $60 \mathrm{yr}$ and older, no further high-acuity cases for those aged $65 \mathrm{yr}$ and older, and retirement from operating room (OR) clinical practice (with possible continuation of non-OR clinical or other non-clinical activities, if desired) at age $70 y r$. These timelines could be extended with satisfactory performance in annual simulation sessions involving assessment and practice in crisis management.

\section{Résumé}

Objectif Pour aborder le vieillissement de la population des professionnels en anesthésie, nous passons en revue les changements pertinents et les implications associés avec l'âge, afin de stimuler des discussions aux niveaux individuels, locaux et nationaux concernant des modifications appropriées de l'exercice de la profession visant à protéger la sécurité des patients.

Constatations principales Dans une enquête de 2013 sur les anesthésiologistes canadiens, $22 \%$ d'entre eux étaient âgés de 55 à 64 ans, $7 \%$ étaient âgés de 65 à 74 ans et $3 \%$ avaient plus de 74 ans. Les aptitudes 
cliniques déclinent avec l'âge, rendant les anesthésiologistes âgés plus susceptibles que leurs plus jeunes collègues d'être associés à des événements indésirables pour les patients. En Ontario, au Québec et en Colombie-Britannique, les anesthésiologistes âgés de plus de 65 ans avaient $50 \%$ de plus de cas de litige et presque deux fois plus de cas impliquant une complication sévère pour le patient que les anesthésiologistes âgés de moins de 51 ans. En l'absence d'évidence probante de détérioration des habiletés, la décision de réduire les activités et de prendre la retraite est largement laissée aux individus en dépit de leur capacité limitée d'autoévaluation des compétences. Cette situation pourrait contribuer à l'augmentation de l'incidence des évènements indésirables et à des mauvais resultats pour les patients.

Conclusions Les organismes de réglementation provinciaux ont des programmes d'évaluation des pairs pour évaluer les médecins au hasard, après une plainte, et à certains âges, mais tous ces programmes ont des limites. La simulation a été largement utilisée pour la formation et l'évaluation dans l'industrie aéronautique, de même que pour les examens de conduite automobile. La simulation peut évaluer la reconnaissance et la gestion des situation de crise, ce qui est fondamental en anesthésiologie, et pas très bien évalués par d'autres méthodes; cela pourrait aider les anesthésiologistes plus âgés au cours de la phase de préretraite de leurs carrières. Un plan standardisé de réduction progressive de l'activité aurait des avantages pour les médecins, leurs départements et leurs patients. Un calendrier suggéré pourrait inclure la cessation des gardes pour ceux qui sont âgés de 60 ans et plus, ne plus faire de cas de haute complexité pour les praticiens âgés de 65 ans et plus, et la cessation des activités cliniques en salle d'opération (avec la possibilité de poursuivre des activités en dehors des salles d'opération ou d'autres activités non cliniques, si désirées) à 70 ans. Ces échéances pourraient être prolongées avec la réussite à des sessions de simulation annuelles impliquant une évaluation et une pratique en gestion de crise.

As the general population ages, there is a similar increase in the number of elderly physicians continuing to practice medicine, including anesthesiology. There are a variety of reasons for this, including financial need and inadequate retirement planning. Importantly, these older physicians may be a necessary resource for the adequate provision of health care in some specialties. ${ }^{1}$ Nevertheless, our clinical abilities are known to decline with age, especially when combined with exposure to lower case volumes. ${ }^{2}$ As a result, aging anesthesiologists are, to some degree, more likely than their younger colleagues to be associated with adverse events that give rise to both patient harm and an increased risk of litigation. ${ }^{3}$ All the same, because of the regional challenges of anesthesiology manpower, it may be desirable to help these individuals remain in appropriate practice as long as they continue to demonstrate clinical competence and do not compromise patient safety.

Tessler et al. reported that anesthesiologists in Ontario, Quebec, and British Columbia who were over the age of $65 \mathrm{yr}$ had a $50 \%$ higher frequency of litigation and an almost twofold greater incidence of reported patient injury compared with anesthesiologists younger than $51 \mathrm{yr}$ of age. ${ }^{3}$ Despite various study limitations, these results remain disturbing. It is not entirely clear what factors contribute to this apparent lapse in the quality of clinical care that older anesthesiologists provide. Furthermore, without overt evidence of deterioration in the level of skills, decisions about reducing clinical activities and retirement are left largely to an individual's self-assessment and judgment of clinical competence; this may contribute, at least in part, to these increased adverse events and poor outcomes. A more structured approach to tapering clinical activities and planning retirement may benefit both individuals and respective anesthesia departments and may ultimately improve patient safety.

Although anesthesiologists usually work within an interprofessional team, they are often the only anesthesia care provider present, making it a challenge to monitor the standard of care. This situation is compounded by the use of potent anesthetic and other vasoactive drugs with

Table 1 Demographics

\begin{tabular}{|c|c|c|c|}
\hline \multirow[t]{2}{*}{ Data source } & \multicolumn{3}{|c|}{ Age (yr) } \\
\hline & $55-64$ & $>65$ & $>74$ \\
\hline United States $2010^{4}$ & 19.7 & 19.8 & \\
\hline United States 2010 anesthesiologists ${ }^{4}$ & 20.8 & 8.3 & \\
\hline $\begin{array}{l}\text { Canadian Medical Association } 2012 \\
\text { specialists }^{\mathrm{a}}\end{array}$ & 25.3 & 16.4 & \\
\hline $\begin{array}{l}\text { Canadian Medical Association } 2012 \\
\text { anesthesiologists }^{\mathrm{a}}\end{array}$ & 26.7 & 12 & \\
\hline $\begin{array}{l}\text { Canadian Anesthesiologists' Society } 2013 \\
\text { survey }^{\text {b }}\end{array}$ & 22 & 7 & 3 \\
\hline $\begin{array}{l}\text { The Ottawa Hospital Anesthesia } \\
\text { Department } 2012^{\mathrm{c}}\end{array}$ & 25.3 & 8 & \\
\hline \multicolumn{4}{|c|}{$\begin{array}{l}\text { Data represent the percentage }(\%) \text { in each age category. } \\
\text { a Canadian Medical Association Masterfile } 2012 .\end{array}$} \\
\hline $\begin{array}{l}\text { b CAS Membership Survey 2013, } \\
\text { communication. }\end{array}$ & P. Ho & ton & personal \\
\hline
\end{tabular}


inherent rapid action that leaves little margin for error, the corresponding rapid time course for problems to become serious, and fewer safety checks (e.g., nurses, pharmacists) than elsewhere in medical practice.

Hence, this narrative review aims to summarize the current evidence on aging in anesthesiology. We searched PubMed using the subjects: "Physician Ageing", "Cognitive Function and Ageing", "Simulation", "Anesthesiologist Ageing", "Mandatory Retirement", and other related terms. Further search for appropriate material was performed after additional review of the reference lists in the searched articles (i.e., the so-called "snowballing" technique). In doing so, we aim to give more senior anesthesiologists and physician leaders insight into potential practice shortcomings that come about with aging. We suggest how aging anesthesiologists might tailor their practice to address aging issues and achieve an honourable and dignified conclusion to their respective careers. We review current methods used to assess competence and propose a strategy for ongoing evaluation of the older anesthesiologist in order to ensure continuing safe practice. We also review the obligations and rights of hospital management with respect to the older physician, with consideration for the applicable human rights legislation and hospital privileges. Our objective is to raise awareness of this issue and to stimulate discussion in prominent organizations, such as the Canadian Anesthesiologists' Society (CAS) or the College of Physicians and Surgeons of Canada (RCPSC), regarding a more systematic methodology than the individual or local measures we currently advocate.

\section{Demographics}

Table 1 outlines the various age demographics of various physician groups. Up to $8.3 \%$ of anesthesiologists ${ }^{4}$ in the United States are older than $65 \mathrm{yr}$ of age. In Canada, the numbers are somewhat higher, at $10-12 \%$, depending on the source of information; however, the activity status of these respondents is not known. For example, at The Ottawa Hospital in 2012, all anesthesiologists older than 65 yr had discontinued on-call duties.

\section{Physiological changes of aging and the practice of anesthesiology}

The chronology and biology of aging varies amongst individuals, and it may be difficult to differentiate between the normal physiological aging process and changes secondary to disease, such as dementia, which has an incidence of $3-11 \%$ in those over $65 \mathrm{yr}^{1}$ Social stressors, illness, fatigue, and substance abuse (with an incidence as high as $15 \%$ in anesthesiologists $)^{5}$ may also have variable effects on competence and are more common with aging.

Aviation experience has shown that performance of stressful and complex tasks as well as quick and effective appropriate decision-making is reduced in older pilots. ${ }^{6}$ In medicine, decreased job satisfaction, burnout, anxiety, depression, and fatigue are more common in older practitioners. ${ }^{7,8}$ In addition, there may be fear of failure and challenges to self-esteem. Older people tend to wake earlier in the morning and fatigue earlier in the day (described as "morningness"), ${ }^{9}$ making them more suited to work in the morning than later in the day. There is a declining ability to cope with on-call stress and sleep disruption along with an increasing susceptibility to fatigue and decreased vigilance. Night on-call work is a commonly cited reason for anesthesiologists to retire early. ${ }^{10}$

Older adults take up to twice as long to process information as they age from their 20 s through to their 70 s. ${ }^{11}$ Analytical processing declines with age, with more reliance on experience, and more premature closure (i.e., failure to consider alternatives to the initial diagnosis). Flexibility and the ability to cope with environmental change are reduced. ${ }^{2}$

The elderly are less likely to adopt new therapies, changing standards of care, and guidelines, ${ }^{2}$ and they are less responsive to traditional continuing medical education (CME) methods. ${ }^{12}$ Nevertheless, the older physician's experience may partly compensate by "pattern recognition" and the ability to see the bigger picture. ${ }^{13}$ Age was a negative predictor of competence in a review of the relationship between age and its impact on medical practice. ${ }^{1}$ There was considerable variability in the group of older physicians, indicating that some older physicians performed at the same or at a higher level than their younger colleagues. Nevertheless, on average, older physicians performed less well than younger physicians: their knowledge base was less likely to be up to date, patient interviews were shorter and blunter, history taking was not comprehensive (often overlooking important details), data gathering was incomplete, and important management strategies were left out.

Data available on neurocognitive changes with advancing age were reviewed by Trunkey. ${ }^{5}$ Aspects of the Wechsler Adult Intelligence Scale (WAIS) decline with advancing age from a score of 100 at age 20-24 yr to a score of 75 at age 70-74 yr. The MicroCog ${ }^{\mathrm{TM}}$ Assessment of Cognitive Functioning in the WAIS is designed to assess reactivity, attention, numeric recall, verbal memory, visuospatial facility, reasoning, and mental calculation. These show a consistent decline with age, although the correlation with clinical ability is not established.

Particularly pertinent to anesthesiology, manual dexterity and visual acuity ${ }^{9}$ are reduced, while physical 
and mental health problems are more common. Arthritis and decreased psychomotor agility may impede the physician's ability to perform technical procedures. Years of repetitive performance may partly compensate, but to a degree which has been poorly documented.

Visual impairments, such as cataracts and glaucoma, may impose serious handicaps if not remedied with appropriate corrective lenses and/or minor surgery. Hearing impairment may begin to manifest at approximately age $40 \mathrm{yr}^{14}$ Common hearing problems in anesthesiologists include presbycusis (hearing impairment in the high frequency range), abnormal loudness perception, tinnitus, and difficulty with sound localization. The problem is worsened with increasing levels of background noise and may interfere with alarm detection. In a study of 188 anesthesiologists aged 28$80 \mathrm{yr}, 66 \%$ had an abnormal audiogram, and $37 \%$ were unaware of their hearing problem. ${ }^{14}$ It is not clear why, but acuity was worse than in the general population up to age $54 \mathrm{yr}$, but it was similar at older ages. Anesthesiologists are often dependent on auditory alarms that are often in competition with substantial background noise. Thirteen percent admitted difficulty detecting operating room alarms, and $7 \%$ had deficits that would be expected to interfere with alarm detection. The frequencies of operating room alarms vary, and the hearing deficit of $39 \%$ of tested anesthesiologists older than $65 \mathrm{yr}$ revealed that one or more alarms were below the threshold of detectability. ${ }^{14}$

\section{Patient safety implications due to ongoing clinical activity of elderly physicians}

\section{Physicians in general}

In a systematic review of physicians in the United States with regard to aging, medical knowledge, and quality of care, quality of care decreased with increasing time in practice, ${ }^{2}$ with elderly physicians being less likely to follow guidelines. Surprisingly, there was less effect on outcomes than expected, ${ }^{13}$ suggesting some compensation through experience (i.e., "pattern recognition"). A longer time from medical school graduation increased the likelihood of disciplinary action by state licensing boards, ${ }^{15}$ with physicians with more than $20 \mathrm{yr}$ in practice more likely to have been disciplined. ${ }^{16,17}$ It was not clear if this was due to increased exposure to complaints, diminishing knowledge or skills, a combination of both, or perhaps other factors. Increasing surgeon age is associated with increased operative mortality with some but not all procedures, ${ }^{18-20}$ especially those with low surgical case volumes. United
States' emergency physicians in pre-retirement years (average age, $57 \mathrm{yr}$ ) were surveyed for concerns about their practice. ${ }^{21}$ Seventy-four percent reported less perceived ability to recover after "night work", $44 \%$ had high emotional exhaustion after a work shift, $36 \%$ had less ability to handle work stress, $28 \%$ had practice-limiting health problems, $25 \%$ were less willing to incorporate new methods into their practice, $42 \%$ had made inadequate financial preparation for retirement, and $44 \%$ feared loss of identity after retiring from practice.

In the United Kingdom, physicians can be referred to the National Clinical Assessment Service for assessment of performance concerns, e.g., clinical difficulties, misconduct, health problems, but not advancing age per se. In a 2011 report of 2009-2010 data, without adjustment for case load or acuity, physicians older than $60 \mathrm{yr}$ were more likely than younger practitioners to be referred for assessment and removed from practice. ${ }^{22}$ Furthermore, from 2001-2012, there were 6,179 referrals, or five per 1,000 physicians per annum. Men were referred 2.5 times as often as women (while there is a 1.4 male:female physician ratio according to the United Kingdom National Health Service). Misconduct was more common in men, but clinical difficulties were equal. Six percent of referrals were anesthesiologists, and late career physicians (older than $55 \mathrm{yr}$ ) were referred almost six times more often than those early in their career (younger than $35 \mathrm{yr}$ ). ${ }^{23}$

\section{Anesthesiology}

Tessler $^{3}$ reported the frequency of successful litigation and disability-weighted claims for anesthesiologists in British Columbia, Ontario, and Quebec from 1993-2002; data were derived from the Canadian Medical Protective Association (adjusted for case volume). Older anesthesiologists tended to care for fewer patients and were involved in less complex procedures. Anesthesiologists older than $65 \mathrm{yr}$ were more likely to have litigation claims ( 1.5 odds ratio [OR]; 95\% confidence interval [CI] 1.14 to 1.97) than those younger than $51 \mathrm{yr}$. Disability-weighted claims were even higher (1.94 OR; 95\% CI 1.41 to 2.67). These increases were consistent for both low and higher acuity cases. The higher cost of the settlements in these actions may indicate more serious complications and patient outcomes.

The anesthesiology profession in Canada should consider this substantive age-related increase a "wakeup" call to examine this issue in more detail. Why do anesthesiologists $65 \mathrm{yr}$ of age and older have a greater incidence of medicolegal actions against them than younger colleagues? Speculative explanations include easier fatigue, less vigilance, deviations from standard practice, and potentially less participation in continuing professional development (CPD). 
A survey of 1,208 active and retired members of the American Society of Anesthesiologists in New England sought information on age-related practice issues. ${ }^{10}$ Although age was not a strong correlate of practice patterns, behaviour, or performance, a significant number of respondents perceived that advancing age was associated with physical and attitudinal changes, which could potentially influence fitness for duty as well as provider and patient wellbeing. Older anesthesiologists tended to work fewer hours (though with many up to 70$79 \mathrm{hr}$ per week), and $60-80 \%$ of institutions did not have policies for reducing on-call activities or restricting practice and stress with advancing age.

Many older anesthesiologists would value objective evaluation of their performance. ${ }^{10}$ In our view, anesthesiologists tend to be more proactive than other physicians in planning for retirement by deciding themselves to retire from practice when they "felt it was time". Nevertheless, results of a systematic review ${ }^{24}$ showed that physicians in general had limited ability to self-assess their competence and abilities and suggested a need for external assessment. "Demands of night call", "difficult cases", "liability issues", "demands of workload", "burnout", and "economic factors" are commonly stated reasons for anesthesiologists' retirement. ${ }^{9}$

Thus, the data are similar across different specialist groups and countries. We have described potential deficiencies in the practice of older physicians, from aging alone to other factors, and specifically in anesthesiology in view of Tessler's ${ }^{3}$ findings. Older anesthesiologists must be aware of the effects of aging that may affect their ability to practice effectively and competently and must deal with them appropriately. In order to benefit themselves and, most importantly, their patients, older anesthesiologists, their colleagues, and leaders in the specialty should adopt strategies for ongoing evaluation with modifications to practice where necessary. We think the available evidence suggests a proactive approach and suggest changing the default position (i.e., continuing practice until there is a problem detected by peers or a critical incident) to an annual review and demonstration of competence by simulation (similar to the aviation industry) once a certain age threshold is met.

\section{Assessment of physicians for age-related decline in competence}

Although some informal assessment by peers does occur, anesthesiologists largely self-assess their coping ability for on-call and/or high-acuity cases. Physicians in general often have limited ability to assess their own competence, hence the necessity for external evaluation. ${ }^{12,24}$ Self- esteem, financial difficulties, lack of other activities, or staff shortages, coupled with poor insight may encourage individuals to continue working perhaps beyond their capabilities. As the physician population ages, more anesthesiologists may potentially remain in the workforce in clinical situations they may be unable to handle. Additional challenges to competence include dysfunctional or antisocial behaviour, failure to participate in CPD, substance abuse, and physical disability. Patients may be harmed due to the inability of aging anesthesiologists to recognize or adequately deal with crises. Cognitive assessment of physicians includes tests such as the MiniCog, MicroCog, Mini-Mental State Exam, and the clock-drawing test, ${ }^{5,17}$ but these do not evaluate crisis management. Physicians have a strong cognitive reserve, resulting from higher education and advanced medical training, that may mask signs of early cognitive impairment. ${ }^{17}$

Regulatory bodies in Canada, such as the College of Physicians and Surgeons of Ontario (CPSO), have peer assessment programs that, in addition to random physician assessments, also mandate assessment after a complaint has been filed. Importantly, additional non-random assessments are performed on physicians in the year in which they reach age $70 \mathrm{yr}$, with repeat assessments every five years thereafter. These assessments are largely in the form of a chart review - a process with obvious limitations. Peer assessment data obtained from the CPSO for 2009-2011 (Table 2) show satisfactory results for $87-91 \%$ of random assessments; however, at age $70 \mathrm{yr}$, the figures drop to 74$83 \%$. Reassessments of physicians who performed poorly occurred in 7-9\% of those in the random group and 15-17\% of those in the age 70 group. $^{\mathrm{A}} \mathrm{A}$ reassessment no longer involves an interview; instead, the physician meets with a review panel consisting of CPSO staff and two physicians from the same discipline who may ask clinical questions similar to those in the RCPSC examinations.

A better assessment method may be the so-called " 360 degree" assessment currently used by the College of Physicians and Surgeons of Alberta and the CPSO. ${ }^{25}$ This evaluation involves multisource feedback from peers, patients, and non-physician colleagues and rates the individual's knowledge, communication skills, overall personality, and collegiality. Nevertheless, other healthcare professionals may have limited insight into expertise in anesthesiology, especially if the physician being assessed selects the persons to provide feedback. Furthermore, patient feedback may be limited by the brief period during which the anesthesiologist spends with the conscious patient. Patients may be satisfied if the analgesia was adequate and nausea and vomiting were treated,

\footnotetext{
${ }^{\text {A }}$ CPSO Annual Report.
} 
Table 2 CPSO peer assessment data from 2009-2011

\begin{tabular}{|c|c|c|c|c|c|c|c|c|c|}
\hline & \multicolumn{3}{|c|}{$\begin{array}{l}\text { Satisfactory } \\
\text { Assessment }\end{array}$} & \multicolumn{3}{|c|}{ Re-Assessment } & \multicolumn{3}{|c|}{$\begin{array}{l}\text { Interview or } \\
\text { Review Panel }\end{array}$} \\
\hline & 2009 & 2010 & 2011 & 2009 & 2010 & 2011 & 2009 & 2010 & 2011 \\
\hline Overall & $83 \%$ & $86 \%$ & $85 \%$ & $11 \%$ & $10 \%$ & $10 \%$ & $6 \%$ & $4 \%$ & $5 \%$ \\
\hline Random & $87 \%$ & $91 \%$ & $91 \%$ & $9 \%$ & $7 \%$ & $7 \%$ & $4 \%$ & $2 \%$ & $2 \%$ \\
\hline Age 70 & $83 \%$ & $74 \%$ & $74 \%$ & $15 \%$ & $17 \%$ & $17 \%$ & $2 \%$ & $9 \%$ & $9 \%$ \\
\hline Age $70+$ & $80 \%$ & $84 \%$ & $84 \%$ & $13 \%$ & $8 \%$ & $8 \%$ & $7 \%$ & $8 \%$ & $8 \%$ \\
\hline
\end{tabular}

$\mathrm{CPSO}=$ College of Physicians and Surgeons of Ontario.

despite unknowingly having experienced a critical incident during anesthesia. In Alberta, physicians who score in the lower third are subjected to an on-site assessment of their clinical practice, with $1 \%$ having been subsequently assessed as requiring remedial training. ${ }^{17}$ Then again, the value of structured clinical observation of operating room practice is limited by the brevity of the encounter as well as the infrequency and unpredictability of crises.

During testing for cognitive impairment, there may be big differences between performance in the test room and in the workplace. The older physician's wisdom and experience often compensate for any cognitive impairment, and this compensatory method fails only in advanced stages of cognitive impairment. ${ }^{9}$

Standards are imposed by other professions with similar responsibilities. The assessment of competence for airline pilots is much more rigorous than for physicians and includes a medical exam every six months, random drug tests, and annual simulation. Simulation failure is grounds for remediation. In Canada, since December 2012, Air Canada $^{\mathrm{TM}}$ pilots may continue to fly beyond age 60 , but only with the flight deck presence of another pilot younger than 60 .

\section{Simulation}

Simulation has been used widely in the aviation industry for pilot training and assessment. It also has uses for assessing competence in automobile driving as well as for military and nuclear power plant settings. ${ }^{26}$ In medicine, there has been increasing interest and application over the last couple of decades, especially for assessment and training for the management of unexpected rare events. ${ }^{27}$ Systematic reviews have confirmed the effectiveness of simulation training for various skills, ${ }^{28}$ and it is highly effective for resuscitation. ${ }^{29}$ Simulation training transfers knowledge and skill sets from the simulated environment to the clinical setting, both for procedural skills ${ }^{30}$ and nontechnical skills for crisis resource management (CRM). ${ }^{31}$ Most of this literature is based on the experience of postgraduate trainees, but a few studies have demonstrated that

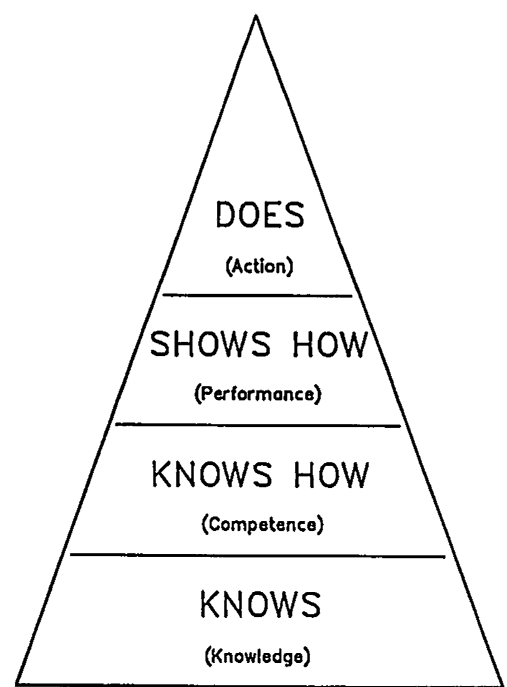

Figure Miller's pyramid. ${ }^{40}$ With permission from: Miller GE. The assessment of clinical skills/ competence/ performance. Acad Med 1990; 65: s63-s7.

simulation-based education is effective for long-term retention of procedural skills and useful for consultantlevel anesthesiologists. ${ }^{32}$

Simulation serves both formative (assessment for learning by identification of weaknesses and deficiencies for correction) and summative (assessment of learning for achievement of an adequate standard of practice) purposes. Importantly, it facilitates assessment of CRM, which is crucial and not well addressed by other assessment methods. ${ }^{33,34}$

Many Canadian consultant-level anesthesiologists, and not just those deemed elderly, fear instructors' judgments and are intimidated by the simulated environment. ${ }^{35}$ Selfdebriefing after a simulated practice may help to overcome this perceived barrier. This refers to debriefing performed by the "learner" him/herself without any instructor, and it is effective for residents learning CRM both individually and with an inter-professional team. ${ }^{36,37}$ This approach could be used for assessing anesthesiologists, especially the elderly who might be most concerned with the instructor's judgment. As yet, however, there are no specific data available for this group.

A recent simulation-based study demonstrated decreasing competency for performing cricothyrotomy, both with increasing age and time from residency, even after standardized training. ${ }^{38}$ This suggests that older anesthesiologists may require more tailored simulation CPD. $^{38}$ The same investigators found that technical and non-technical skills in post-graduate trainee anesthesiologists were not independent of each other, ${ }^{39}$ suggesting that assessment of one type of skill may allow extrapolation to others. Finally, a recent systematic review on the role of simulation in CPD for acute care physicians 
(including anesthesiologists) found only 30 studies focusing on the effectiveness of simulation-based education for CPD. ${ }^{40}$ A limitation, however, was that none of these studies focused on older practitioners. Ten of the studies in that systematic review described a positive learning experience with simulation and a perceived improved impact on clinical practice using selfassessment. Most demonstrated both immediate and/or sustained improvements in educational outcomes.

Miller's pyramid (Figure) describes a hierarchical framework for assessment, from the basic "knows" level (knowledge only), followed by the "knows how" level (can describe how to apply knowledge), through to the "shows how" (simulation) level, with the "does" (clinical setting) level being the highest. ${ }^{41}$ While simulation assessment for physicians remains controversial, ${ }^{42}$ it is currently the only way to "show how", especially for management of unpredictable rare clinical crises. Simulation might be an effective tool to assess competency and (re)train anesthesiologists who are seeking active clinical status. ${ }^{43}$ These physicians are a heterogeneous group and not always elderly. Boulet showed that expert assessment of video performances was appropriate for setting standards on several mannequin-based emergency scenarios. ${ }^{44}$ In the systematic review by Khanduja et al., ${ }^{45}$ the authors found only nine studies reporting their only objective as the psychometric properties of the assessment of simulation performance, mainly establishing the discriminative validity of an assessment tool and concentrating on a single aspect of evidence of validity. Murray suggested that there is satisfactory validity for assessments of simulation performance of staff anesthesiologists from university and community hospitals, anesthesiology residents, and medical students, ${ }^{46}$ but Boulet and Murray concluded that "it is not clear how judgments of minimal competence should or could be made". 42

Simulation has been used to assess the ability of student nurse anesthetists and anesthesia resident physician trainees to manage crises. ${ }^{46}$ Although there are limited specific data about elderly anesthesiologists and simulation-based education, literature on the effectiveness of simulation is growing quickly, including the demonstration of skills transfer from the simulation centre to the operating room and the impact on patient outcome and safety. ${ }^{31,45}$ Older physicians may consider it unfair to undergo regular evaluations when younger physicians do not, but older physicians are considered a group with higher risks who require specific attention and opportunities to maintain competence. We suggest exploring the use of simulation to assist elderly anesthesiologists during the pre-retirement phase of their careers

\section{Medicolegal issues $^{B}$}

The law in a nutshell

Physicians older than $65 \mathrm{yr}$ may face societal, peer, or institutional pressure to retire from practice. Reasons include: (i) the need to make positions and resources available to recruit recently trained physicians who may have skills that are more up to date; (ii) to allow for a more dignified departure from practice; and (iii) to maintain a high standard of patient care and safety given the previously mentioned problems identified with the practice of some older physicians. The following information is intended to be helpful for older physicians considering or being asked to consider retirement from practice.

Canadian provincial and federal human rights legislation prohibits discrimination in the workplace on various grounds, including mandatory retirement on the basis of age (e.g., refer to the Ontario Human Rights Code). ${ }^{47}$ These laws are available on the provincial websites. ${ }^{48}$ This legislation does not mean that employers cannot have retirement programs, only that they cannot be mandatory. ${ }^{49}$ Nevertheless, there are exceptions - federal judges must retire at age 70-75 and senators at age 75 . With regard to mandatory retirement, the fundamental principle is that the ability to do a job should be determined on an individual basis and should not be related to age.

Certain rights afforded to employees under provincial human rights legislation may be limited if an employer can demonstrate that there is a bona fide occupational requirement (BFOR). ${ }^{50}$ If age is considered a BFOR, the employer may set an age for mandatory retirement. This logically could be a concern for hospital-based physicians in certain disciplines where the work is physically or technically demanding and involves issues of patient safety.

Legislation also requires employers to accommodate older workers' needs, which may include part-time work, job redesign, reduced hours, or job retraining. This could include a phased retirement policy (as described below).

Employers may also accommodate older workers if they demonstrate through performance evaluation that they can still perform their duties. In certain industries, however, it may be impossible to conduct an appropriate performance evaluation for various reasons (e.g., safety concerns). This is one of the reasons why firefighters are required to retire at age $60 .^{51}$

\footnotetext{
B We acknowledge the assistance of Kyle Lavender JD, Associate, LaBarge Weinstein LLP, Ottawa, ON, Canada in preparing the Medicolegal section.
} 
Most physicians are not considered employees and may "fall between the cracks" with regard to human rights and employment law. Hospital-based doctors are governed by hospital and health region bylaws within which practice privileges for medical staff are issued and approved annually. Some hospitals require physicians to change their clinical status (to inactive) or to retire at $65-70 \mathrm{yr}$ of age. In a court challenge of this requirement (Stoffman vs Vancouver General Hospital), ${ }^{52}$ a group of physicians ultimately lost their challenge under the Charter of Rights and Freedoms at the Supreme Court of Canada. In that case, the court appeared receptive to the hospital's argument that it needed staff positions for younger more recently trained physicians as well as to arguments that a program of skill testing would be disruptive to staff and too costly to implement.

With respect to medical partnerships, provincial human rights legislation is applicable only when a partner may be designated as an employee of the partnership. In a recent Supreme Court of Canada decision, ${ }^{53}$ the court held that the British Columbia Human Rights Tribunal did not have jurisdiction to hear a complaint brought by a partner of a law firm challenging the firm's mandatory retirement policy. The court found that, in the absence of any genuine control over a partner with respect to significant decisions affecting the workplace, the provincial human rights legislation was not applicable as the partner was not in an employment relationship with the partnership. Although this case clearly illustrates that mandatory retirement provisions may be included in partnership agreements, it is still possible for a partner to be considered an employee if they have little control or influence over the partnership's management. Physicians in partnerships with a mandatory retirement policy or those contemplating the adoption of such a policy should review this decision in detail.

Canadian law at present appears to allow for mandatory retirement policies where safety may be an issue. The courts have stipulated that employers and hospital boards must evaluate and allow for continued clinical work where there is evidence of clinical competence. ${ }^{52,54}$ In anesthesiology departments, the most likely implementation of a phased retirement program would be (i) a departmental policy at the university or hospital level or (ii) in a section of the applicable partnership agreement. Each of these would need to outline continuing educational and examination requirements as well as applicable mechanisms for dispute resolution. The pressure to introduce programs to bolster patient safety will only increase the demand for such programs in the future. The phased retirement policy outlined below provides an example of a measured and justifiable limitation to the rights of anesthesiologists. In our view, the courts would likely uphold the implementation of such a policy.
What does this mean for older physicians who are approaching an age where retirement is considered a societal or professional norm? First, they must be familiar with their departmental, health region, and hospital bylaws. If these address mandatory retirement or changes in practice and if they wish to continue their practice, they should obtain legal advice and investigate the pertinent provincial legislation. Willingness to undergo performance evaluation and the support of the department head might also be required.

\section{What can the anesthesiologist do?}

Warner ${ }^{55}$ advocates not to "rush to take away the keys", but instead, to begin by reducing night call (to avoid the associated fatigue) and shortening schedules.

We suggest developing a plan for retirement ${ }^{12}$ that includes a shorter work week, elimination of on-call night shifts, a gradual reduction in responsibilities, and/or a modification in the scope of practice. High-acuity cases that require rapid cognitive processing are best avoided, together with other aspects of anesthesia practice that have a higher frequency of sudden and challenging cardiovascular and respiratory emergencies. In addition, for the higher acuity cases, more time should be scheduled for the assessment of patients with complex medical problems. Furthermore, additional assistance for older anesthesiologists (see below) should be provided if they are scheduled for more complex cases that cannot otherwise be avoided.

Assessment and maintenance of a healthy lifestyle ${ }^{11}$ could include an annual "executive" medical examination (or equivalent) at ages older than $60 \mathrm{yr}$, with a detailed report provided to the department head. In addition, it is important to listen carefully to concerns expressed by colleagues and friends, noting and appropriately pursuing any symptoms suggestive of potential cognitive decline. Perhaps an annual cognitive function assessment should be undertaken at age 65-70 yr and older, again with a report provided to the department head. This could be one part of an annual fitness-to-practice assessment.

\section{What can the anesthesiology department do?}

The weakness of self-assessment limits the effectiveness of these suggestions in assisting departments in their decisions regarding their aging colleagues, hence the need to be proactive and to consider introducing a structured "winding down" policy. Older anesthesiologists should be assigned to less challenging work; this should be possible in most departments. Provision of more assistance for the older anesthesiologist from other staff anesthesiologists, residents, or anesthesia assistants 
should be considered for certain cases as appropriate (c.f., the presence of a second pilot on the flight deck in aviation), but arguably, this may be logistically difficult. Indeed, there is a lack of published data to indicate whether or not this so-called "supervisory practice model" 56 improves patient safety and reduces malpractice lawsuits. The older anesthesiologist may be less suited for on-call activities and higher acuity cases, and anesthesiology departments may need to allow for adjustments in scheduling when planning recruitment. The department may need to assist with acquiring appropriate assessments to ensure fitness-to-practice and, ideally, should conduct the appropriate performance evaluations internally rather than relying on external regulatory body assessments. There should be on-site observation of practice by anesthesiologists appointed by the university (ideally not the site chief per se, but perhaps younger colleagues maybe ten or more years out of residency). This could also be a responsibility of the health region. Some anesthetic partnership practices are establishing phased retirement plans $^{57}$ similar to the proposal below with progressive reductions in on-call and OR schedule assignments.

\section{Structured "winding down" of clinical activities}

Perhaps there should be a role for the CAS, in a similar manner as that for the CPSO but with a focus on the pertinent anesthesia issues. A high-level national approach from the CAS or RCPSC could provide for a system change that could be standardized and include non-hospital practitioners.

In the absence of a national policy, we suggest local initiatives. Table 3 shows an example of a structured winding down of clinical activities for the anesthesiologist nearing retirement. Of course, the anesthesiologist may reduce activities earlier than these timelines within the limits of departmental policies. Acknowledging the variability in the aging process, the anesthesiologist who wants to make changes in practice activities at an older age should demonstrate clinical competence annually using simulation sessions to assess and practice crisis management. It could be reasonably argued that all anesthesiologists should perform this assessment annually, but it may be more practical and acceptable to begin with this higher risk group. The financial and logistical considerations for this venture would need to be developed locally.

There are potential benefits to this approach for patients, individual physicians, partnerships, and departments. Although specific associations between older of physicians and adverse events can be difficult to ascertain, patient safety remains paramount. Physicians will have less uncertainty about their end-of-career course with proper planning that facilitates less stress and provides protection from external
Table 3 An example of structured pre-retirement "winding down" of clinical activities

\begin{tabular}{|c|c|}
\hline $\begin{array}{l}\text { Age } \\
(\mathrm{yr})\end{array}$ & Practice activities \\
\hline $60-64$ & $\begin{array}{l}\text { - no further on-call duties (to avoid interrupted sleep, stress } \\
\text { of higher case acuity, limited help available to deal with } \\
\text { crises) } \\
\text { - recommend annual simulation CPD to practice and assess } \\
\text { crisis management }\end{array}$ \\
\hline $65-69$ & $\begin{array}{l}\text { - no further high-intensity/high-acuity cases (to be defined } \\
\text { for the individual, with no exceptions unless in a life-or- } \\
\text { limb crisis) }\end{array}$ \\
\hline$>70$ & $\begin{array}{l}\text { - retirement from operating room clinical practice } \\
\text { - if desired, replace with non-operating room clinical or non- } \\
\text { clinical activities such as pre-anesthesia assessment clinic, } \\
\text { administration, research, mentoring, education }\end{array}$ \\
\hline
\end{tabular}

$\mathrm{CPD}=$ Continuing Professional Development

Note: the anesthesiologist who wishes to make changes in practice activities at an older age should demonstrate clinical competence annually using simulation sessions to assess and practice crisis management.

pressures to carry out cases with which they may feel less at ease. With this in place, perhaps regulatory bodies would even consider forgoing their own performance reviews. If adverse events do occur despite this approach, then at least the individuals will have shown due diligence to ensure a responsible approach and insight into this aspect of their work activities towards the end of their career. Similarly, depending on local factors and policies, the department will also have shown a responsible approach and insight into this aspect of the work activities of individuals towards the end of their careers. This may also lead to an improved ability to plan for hiring personnel to cover on-call and to take care of higher acuity cases. Importantly, the individual hospital and anesthesiology departments will benefit from the continued presence of practicing elderly physicians who should be less stressed yet still willing to be present for the educational benefit of their less experienced colleagues.

\section{Conflict of interest None declared.}

Open Access This article is distributed under the terms of the Creative Commons Attribution Noncommercial License which permits any noncommercial use, distribution, and reproduction in any medium, provided the original author(s) and the source are credited.

\section{References}

1. Eva $K W$. The aging physician: changes in cognitive processing and their impact on medical practice. Acad Med 2002; 77: S1-6.

2. Choudry NK, Fletcher RH, Soumerai SB. Systematic review: The relationship between clinical experience and quality of health care. Ann Intern Med 2005; 142: 260-73. 
3. Tessler MJ, Shrier MD, Steele RJ. Association between anesthesiologist age and litigation. Anesthesiology 2012; 116: 574-9.

4. American Medical Association. Physician Characteristics and Distribution in the U.S. Smart DR (Ed.). Washington, DC, American Medical Association; 2006; 1-2.

5. Trunkey DD, Botney $R$. Assessing competency: a tale of two professions. J Am Coll Surg 2001; 192: 385-95.

6. Hardy DJ, Parasuraman R. Cognition and flight performance in older pilots. J Exp Psychol Appl 1997; 3: 313-48.

7. Clark RF. A midlife crisis in academic emergency medicine. Ann Emerg Med 1999; 34: 562-4.

8. Guntupalli KK, Fromm RE Jr. Burnout in the internist-intensivist. Intensive Care Med 1995; 22: 625-30.

9. Katz JD. Issues of concern for the aging anesthesiologist. Anesth Analg 2001; 92: 1487-92.

10. Travis $K W$, Mihevc NT, Orkin FK, Zeitlin GL. Age and anesthetic practice: a regional perspective. J Clin Anesth 1999; 11: 175-86.

11. Durning SJ, Artino AR, Holmboe E, Beckman TJ, van der Vleuten $C$, Schuwirth L. Aging and cognitive performance: challenges and implications for physicians practicing in the $21^{\text {st }}$ century. J Contin Educ Health Prof 2010; 30: 153-60.

12. Lee L, Weston W. The aging physician. Can Fam Physician 2012; 58: $17-8$.

13. Norman $G$, Young $M$, Brooks $L$. Non-analytical models of clinical reasoning: the role of experience. Med Educ 2007; 41: 1140-5.

14. Wallace MS, Ashman MN, Matjasko MJ. Hearing acuity of anesthesiologists and alarm detection. Anesthesiology 1994; 81: 13-28.

15. Kohatsu ND, Gould D, Ross LK, Fox PJ. Characteristics associated with physician discipline: a case-control study. Arch Intern Med 2004; 164: 653-8.

16. Morrison J, Wickersham MS. Physicians disciplined by a state medical board. JAMA 1998; 279: 1889-94.

17. LoboPrabhu SM, Molinari VA, Hamilton JD, Lomax JW. The aging physician with cognitive impairment: approaches to oversight, prevention, and remediation. Am J Geriatr Psychiatry 2009; 17: 445-54.

18. Waljee JF, Greenfield LJ, Dimick JB, Birkmeyer JD. Surgeon age and operative mortality in the United States. Ann Surg 2006; 244 : 353-62.

19. Hartz AJ, Kuhn EM, Pulido J. Prestige of training programs and experience of bypass surgeons as factors in adjusted mortality rates. Med Care 1999; 37: 93-103.

20. O'Neill L, Lanska DJ, Hartz A. Surgeon characteristics associated with mortality and morbidity following carotid endarterectomy. Neurology 2000; 55: 773-81.

21. Goldberg $R$, Thomas $H$, Penner $L$. Issues of concern to emergency physicians in pre-retirement years: a survey. J Emerg Med 2011; 40: 706-13.

22. National Clinical Assessment Service. Concerns About Professional Practice and Associations With Age, Gender, Place of Qualification and Ethnicity - 2009/10 data. London: NCAS, 2011. Available from URL: http://www.ncas.nhs.uk/publications (accessed June 2014).

23. Donaldson LJ, Panesar SS, McAvoy PA, Scarrott DM. Identification of poor performance in a national medical workforce over 11 years: an observational study. BMJ Qual Saf 2014; 23: 147-52.

24. Davis DA, Mazmanian PE, Fordis $M$, Van Harrison $R$, Thorpe $K E$, Perrier $L$. Accuracy of physician self-assessment compared with observed measures of competence: a systematic review. JAMA 2006; 296: 1094-102.

25. Dubinsky I, Jennings K, Greengarten M, Brans A. 360 degree physician performance assessment. Healthc Q 2010; 13: 71-6.
26. Flin $R, O^{\prime}$ Connor $P$, Crichton $M$. Safety at the Sharp End: A Guide to Non-Technical Skills. Aldershot: Ashgate Publishing Limited; 2008 .

27. Tetzlaff JE. Assessment of competence in anesthesiology. Curr Opin Anaesthesiol 2009; 22: 809-13.

28. Cook DA, Hatala R, Brydges $R$, et al. Technology-enhanced simulation for health professions education: a systematic review and meta-analysis. JAMA 2011; 306: 978-88.

29. Mundell WC, Kennedy CC, Szostek JH, Cook DA. Simulation technology for resuscitation training: a systematic review and meta-analysis. Resuscitation 2013; 84: 1174-83.

30. Lund F, Schultz JH, Maatouk I, et al. Effectiveness of IV cannulation skills laboratory training and its transfer into clinical practice: a randomized, controlled trial. PLoS One 2012; 7: e32831.

31. Boet $S$, Bould MD, Fung L, et al. Transfer of learning and patient outcome in simulated crisis resource management: a systematic review. Can J Anesth 2014; 61: 571-82.

32. Boet $S$, Borges BC, Naik VN, et al. Complex procedural skills are retained for a minimum of $1 \mathrm{yr}$ after a single high-fidelity simulation training session. Br J Anaesth 2011; 107: 533-9.

33. Boulet JR, Murray DJ. Simulation-based assessment in anesthesiology: requirements for practical implementation. Anesthesiology 2010; 112: 1041-52.

34. Devitt JH, Kurrek MM, Cohen MM, Cleave-Hogg D. The validity of performance assessments using simulation. Anesthesiology 2001; 95: 36-42.

35. Savoldelli GL, Naik VN, Hamstra SJ, Morgan PJ. Barriers to use of simulation-based education. Can J Anesth 2005; 52: 944-50.

36. Boet $S$, Bould MD, Sharma B, et al. Within-team debriefing versus instructor-led debriefing for simulation-based education: a randomized controlled trial. Ann Surg 2013; 258: 53-8.

37. Boet $S$, Bould MD, Bruppacher HR, Desjardins F, Chandra DB, Naik VN. Looking in the mirror: self-debriefing versus instructor debriefing for simulated crises. Crit Care Med 2011; 39: 1377-81.

38. Siu $L W$, Boet $S$, Borges $B C$, et al. High-fidelity simulation demonstrates the influence of anesthesiologists' age and years from residency on emergency cricothyroidotomy skills. Anesth Analg 2010; 111: 955-60.

39. Riem N, Boet $S$, Bould MD, Tavares W, Naik VN. Do technical skills correlate with non-technical skills in crisis resource management: a simulation study. Br J Anaesth 2012; 109: 723-8.

40. Naik VN, Brien SE. Review article: Simulation: a means to address and improve patient safety. Can J Anesth 2013; 60: 192200.

41. Miller GE. The assessment of clinical skills/competence/ performance. Acad Med 1990; 65: S63-7.

42. Boulet JR, Murray D. Review article: Assessment in anesthesiology education. Can J Anesth 2012; 59: 182-92.

43. DeMaria S Jr, Samuelson ST, Schwartz AD, Sim AJ, Levine AI. Simulation-based assessment and retraining for the anesthesiologist seeking reentry to clinical practice: a case series. Anesthesiology 2013; 119: 206-17.

44. Boulet JR, Murray D, Kras J, Woodhouse J. Setting performance standards for mannequin-based acute-care scenarios: an examinee-centered approach. Simul Healthc 2008; 3: 72-81.

45. Khanduja PK, Bould D, Boet S, Naik VN. Simulation and the maintenance of competence in the acute medical specialties - a systematic review. Simul Healthc 2013; 8: 547-8.

46. Murray DJ, Boulet JR, Kras JF, McAllister JD, Cox TE. A simulation-based acute skills performance assessment for anesthesia training. Anesth Analg 2005; 101: 1127-34.

47. Human Rights Code RSO. 1990, Chapter H. 19.

48. Canadian Human Rights Commission - Government of Canada. Available from URLs: http://www.chrc-ccdp.ca/index.html; http://www.albertahumanrights.ab.ca/; http://www.bchrt.bc.ca/; 
http://www.manitobahumanrights.ca; http://www.gnb.ca/hrc-cdp/ index-e.asp; http://www.justice.gov.nl.ca/hrc/index.html; http:// nwthumanrights.ca; http://www.nhrt.ca/splash.html; http://human rights.gov.ns.ca; http://www.ohrc.on.ca/en; http://www.gov.pe. ca/humanrights/; http://www.cdpdj.qc.ca/; http://www.shrc.gov. sk.ca; http://www.yhrc.yk.ca (accessed June 2014).

49. Canadian Charter of Rights and Freedoms, Part 1 of the Constitution Act 1982.

50. Mandatory retirement as a bona fide occupational requirement, OHRC discussion paper.

51. Gill V. Hamilton Professional Firefighters Association 2012 HRTO 1506.
52. Stoffman V. Vancouver General Hospital, 19903 SCR 483.

53. McCormick v. Fasken Martineau DuMoulin LLP 2014 SCC 39.

54. Canada v. Martin 1994 2FC 524.

55. Warner MA. More than just taking the keys away. Anesthesiology 2012; 116: 501-3.

56. Gilmour IJ. Anesthesiologist age and litigation: what is the association? Anesthesiology 2012; 117: 1137-8.

57. Lowes $R$. The graceful goodbye: how groups phase out their older doctors. Med Econ 1998; 75: 72-4, 77-8, 80. 